\title{
THỦ TỤC PHÂN TÍCH KIỂM TOÁN ƯớC TÍNH SAI SÓT VÀ RỦI RO SAI SÓT TRỌNG YẾU CÁC KHOẢN MỤC KẾ TOÁN DỰA TRÊN CƠ SỞ CỦA LUẬT BENFORD
}

\author{
TRÀN THỨ BA \\ *Truòng Đại học Công nghiệp Thành phố Hồ Chí Minh \\ tranthuba@iuh.edu.vn
}

Tóm tắt. Luật Benford được biết đến như một công cụ hỗ trợ phân tích để phát hiện ra sự sai sót trong dữ liệu kế toán của doanh nghiệp. Nghiên cứu sẽ trình bày kết quả của sự kết hợp của luật Benford và lý thuyết xác suất thống kê để xây dựng thủ tục phân tích ước tính mức sai sót và rủi ro có sai sót trọng yếu đối với khoản mục kể toán. Đồng thời vận dung lý thuyết thống kê Bayes để chỉ ra các vùng (hay tập số) có khả năng tiềm ẩn sai sót (hay sự gian lận) và chỉ ra một số thông tin đặc trưng nhằm hướng dẫn cho Kiểm toán viên kiểm tra chi tiết một cách nhanh chóng, tối ưu về thời gian mà đảm bảo được độ chính xác. Về ý nghĩa, kết quả của nghiên cứu này sẽ giúp cho kiểm toán viên có thể ước tính được mức sai sót (cả số tương đối và tuyệt đối) để so sánh với mức trọng yếu thực hiện của khoản mục kế toán. Đồng thời, chỉ ra các vùng có khả năng xảy ra gian lận thể hiện qua bảng xác suất hậu nghiệm kết hợp với kết quả của phân tích Benford. Những thông tin đó, sẽ giúp cho kiểm toán viên hình thành ý kiến kiểm toán hay ra quyết định kiểm tra chi tiết để đạt được độ tin cậy mà tối ưu về thời gian và chi phí kiểm toán.

Keywords. Luật Benford, ước tính sai sót, rủi ro sai sót, kiểm toán, thống kê ứng dụng, thống kê kiểm toán

\section{AUDITING ANALYSIS TO ESTIMATE ERROR AND RISK OF MATERIAL MISSTATEMENT OF ACCOUNTING ITEMS BASED ON THE BASIS OF BENFORD LAW}

\begin{abstract}
Benford Law is known as an analytical tool to detect errors in the accounting data of the business. The paper presents the results of a combination of Benford's law and statistical probability theory to construct a model for estimating error rates and the risk of material misstatement of accounting items. At the same time, use Bayesian statistical theories to identify areas (or sets of numbers) with the potential for errors (or fraud) and to show out some specific information to instruct the auditors to check quickly, optimal time to ensure accuracy. In terms of meaning, the results of this research will help the auditor to estimate errors (both relative and absolute) for comparison with the materiality level of the accounting items. At the same time, indicate potential areas of fraud as shown in the posterior probability table associated with the results of the Benford analysis. Such information will help the auditor to formulate auditing opinions or make detailed auditing decisions to achieve optimum reliability in terms of time and auditing costs.

Keywords: Benford law, error estimation, risk of errors, audit, application statistics, audit statistics
\end{abstract}

\section{GIỚI THIỆU}

Gian lận số liệu kế toán làm bóp méo thông tin tài chính của doanh nghiệp làm ảnh hưởng không tốt đến nền kinh tế của quốc gia. Việc nghiên cứu để hoàn thiện hơn các phương pháp hay thủ tục kiểm toán để đáp ứng sự kỳ vọng của các nhà đầu tư (người sử dụng báo cáo tài chính) là hết sức cần thiết trong giai đoạn các quốc gia đang cố gắng để gia nhập TPP, mà đặc biệt là Việt nam - kiểm toán và đào tạo kiểm toán của Việt Nam. Nghiên cứu này sẽ giới thiệu đến các kiểm toán viên một mô hình (hay hệ thống các phương pháp toán) để ước lượng mức sai sót và rủi ro có sai sót trọng yếu nhằm có thể nhận diện và phát hiện ra sự gian lận trong dữ liệu kế toán. Đồng thời mô hình cũng chỉ ra những vùng có khả năng tiềm ẩn sự gian lận hoặc có nhiều sai sót để hướng dẫn kiểm toán viên kiểm tra chi tiết.

\section{CƠ SỞ LÝ THUYẾT VÀ CÁC KHÁI NIỆM}




\subsection{Giới thiệu luật Benford}

Luật Benford thật sự đã cung cấp cho kiểm toán viên một công cụ (phương pháp) đơn giản và hiệu quả trong việc nhận diện và phát hiện sai sót (hoặc gian lận) trong số liệu kế toán. Luật Benford được khám phá dựa trên các nghiên cứu thực nghiệm đã cho thấy tần số xuất hiện của các chữ số hàng đầu của một số $(1,2, \ldots, 9)$ trong các tập dữ liệu là không bằng nhau. Các nghiên cứu của các nhà khoa học như Nigrini (1996), Durtschi, C. (2004), Berger and T.P Hill (2011) đã cho thấy có hơn $30 \%$ các số bắt đầu với chữ số 1 , và tỷ lệ này giảm dần đối với các số bắt đầu với các chữ số lớn hơn cho đến chữ số 9 và các kết quả nghiên cứu này tuân theo phân phối logarit cơ số 10 , hay nói đúng hơn các tỷ lệ (tần suất) xuất hiện các chữ số đầu dần đến giá trị được tính theo công thức (1)[1].

$$
P\left(D_{1}=d_{1}\right)=\log _{10}\left(1+\frac{1}{d_{1}}\right)
$$

Trong đó,

$+\mathrm{D}_{1}$ là vị trí đầu tiên trong số (trị số)

$+\mathrm{d}_{1}$ là chữ đầu tiên $\left(\mathrm{d}_{1}\right.$ có thể nhận một trong các chữ số là $\left.1,2,3, \ldots, 9\right)$.

$+\mathrm{P}$ là xác suất

Thực hiện ước tính các tỷ lệ cho các chữ số đầu theo công thức (1) trên MS Excel 2010 ta được kết quả như bảng sau (bảng 1). Sử dụng công thức này thì tỷ lệ các số bắt đầu với chữ số 1 thì khoảng 30,1\% trong khi tỷ lệ các số bắt đầu với chữ số 9 thì chỉ $4.6 \%$. Kết quả tính toán phù hợp với Nigrini (1996) và Durtschi, C. (2004).

Bảng 1: Tỷ lệ kỳ vọng được tính theo luật Benford (gọi là tỷ lệ Benford)

\begin{tabular}{|c|c|c|}
\hline \multirow{2}{*}{ Chứ số } & \multicolumn{2}{|c|}{ Tỷ lệ Benford } \\
\cline { 2 - 3 } & Vị trí đầu & Vị trí thứ hai \\
\hline 0 & $X$ & 0.1197 \\
\hline 1 & 0.3010 & 0.1139 \\
\hline 2 & 0.1761 & 0.1088 \\
\hline 3 & 0.1249 & 0.1043 \\
\hline 4 & 0.0969 & 0.1003 \\
\hline 5 & 0.0792 & 0.0967 \\
\hline 6 & 0.0669 & 0.0934 \\
\hline 7 & 0.0580 & 0.0904 \\
\hline 8 & 0.0512 & 0.0876 \\
\hline 9 & 0.0458 & 0.0850 \\
\hline
\end{tabular}

Nguồn: Tác giả tính toán

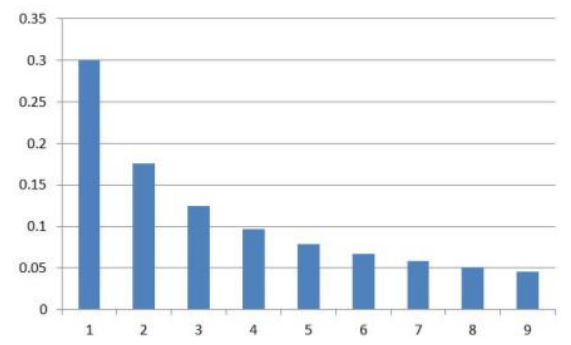

Hình 1: Đồ thị phân bố xác suất của các chữ số đầu tiên 
Luật Benford đã được nhiều nhà khoa học trên thế giới vận dụng như một công cụ hiệu quả để phân tích và kiểm tra sự trung thực và hợp lý các tập số liệu trong đời sống [2 \& 3]. Đặc biệt, các tập dữ liệu kế toán như: doanh thu, chi phí, thuế, ... đều có thể áp dụng kỹ thuật phân tích Benford [4].

\subsection{Lý thuyết xác suất thống kê}

Các kiến thức của xác suất và thống kê toán mà cụ thể là công thức xác suất đầy đủ, công thức Bayes và các lý thuyết về ước lượng, kiểm định giả thuyết cũng được vận dụng trong nghiên cứu này để xác định rủi ro sai sót của khoản mục, khả năng xảy ra sai sót trên các tập hợp số thuộc khoản mục kế toán đang được kiểm tra và xác định khoảng tin cậy cho các tỷ lệ tổng thể để kiểm tra giả thiết kiểm toán.

Công thức xác suất đầy đủ

Giả sử $A_{i}(i=1,2, \ldots, \mathrm{n})$ là một hệ biến cố đầy đủ, khi đó với mọi biến cố $\mathrm{A}$ (trong cùng phép thử) ta có

Hơn nữa, ta có

$$
\mathrm{P}(\mathrm{A})=\mathrm{P}\left(\mathrm{A}_{1}\right) \cdot \mathrm{P}\left(\mathrm{A} \mid \mathrm{A}_{1}\right)+\mathrm{P}\left(\mathrm{A}_{2}\right) \cdot \mathrm{P}\left(\mathrm{A} \mid \mathrm{A}_{2}\right)+\ldots+\mathrm{P}\left(\mathrm{A}_{\mathrm{n}}\right) \cdot \mathrm{P}\left(\mathrm{A} \mid \mathrm{A}_{\mathrm{n}}\right)
$$

$$
\mathrm{P}\left(\mathrm{A}_{1}\right)+\mathrm{P}\left(\mathrm{A}_{2}\right)+\ldots+\mathrm{P}\left(\mathrm{A}_{\mathrm{n}}\right)=1
$$

Công thức Bayes

Với $A_{i}(i=1,2, \ldots, \mathrm{n})$ là một hệ biến cố đầy đủ, với mọi biến cố $\mathrm{A}$ (trong cùng phép thử) sao cho $\mathrm{P}(\mathrm{A})>0$. Khi đó, công thức Bayes xác định như sau

$$
\mathrm{P}\left(\mathrm{A}_{\mathrm{k}} \mid \mathrm{A}\right)=\mathrm{P}\left(\mathrm{A}_{\mathrm{k}}\right) \cdot \mathrm{P}\left(\mathrm{A} \mid \mathrm{A}_{\mathrm{k}}\right) / \mathrm{P}(\mathrm{A})
$$

Với $\mathrm{P}(\mathrm{A})$ được xác định theo công thức xác suất đầy đủ trên.

\section{Phuoong pháp Ước luợng và Kiểm định giả thiết}

Phương pháp ước lượng và kiểm định giả thiết các tham số (tỷ lệ, trung bình, phương sai) của tổng thể được thực hiện theo [6].

\subsection{Các khái niệm cơ bản}

Rủi ro sai sót và rủi ro sai sót trọng yếu: Rủi ro sai sót là khả năng hay xác suất xảy ra sai sót trong việc ghi nhận/xủ lý số liệu. Nếu sai sót xảy ra là trọng yếu thì ta gọi khả năng xảy ra xảy ra sai sót là rủi ro sai sót trọng yếu.

Thông tin được coi là trọng yếu có nghĩa là nếu thiếu thông tin đó hoặc thiếu tính chính xác của thông tin đó sẽ ảnh hưởng đến các quyết định của người sử dụng báo cáo tài chính. Mức trọng yếu tuỳ thuộc vào tầm quan trọng và tính chất của thông tin hay của sai sót được đánh giá trong hoàn cảnh cụ thể. Mức trọng yếu là một ngưỡng, một điểm chia cắt chứ không phải là nội dung của thông tin cần phải có. Tính trọng yếu của thông tin phải xem xét cả trên phương diện định lượng và định tính.

\section{Phân phối Benford}

Hơn 30 năm qua đã có rất nhiều công trình nghiên cứu bao gồm các kết quả nghiên cứu thực nghiệm và các nghiên cứu lý thuyết nhằm giải thích các con số Benford hay luật Benford (A. Berger \& T.P. Hil, 2011). Hầu hất các tập số kế toán là các tập số Benford hay nói cách khác các tập số liệu kế toán luôn tuân theo luật Benford [4].

Một tập dĩ liệu nghiên cúu được xác định là tuân theo Luật Benford, khi đó tần suất của chũ số đầu của các số trong tập dũ liệu được gọi là xác suất hay khả năng xuất hiện của nó trong tập dũ liệu đó.

Một tập dũ liệu nghiên cúu mà tỷ lệ kỳ vọng của các chũ số đầu được xác định theo công thức (1) được gọi là tập dũ liệu có phân phối Benford. Hay tuân theo luật Benford.

\section{Vùng kiểm tra dũ liệu}

Chũ số đầu của số là chũ số hang đầu tiên của một trị số được xác định là một trong các chũ số thuộc tập hơp [1, 2, 3, 4, 5, 6, 7, 8, 9].

Kí hiẹu: $d_{l} \quad\left(d_{1}=1,2,3, \ldots, 9\right)$

Các chữ số đầu của một số phải khác không, do đó, đôi khi người ta vẫn gọi là chữ số đầu có nghĩa để chỉ chữ số hàng đầu khác không khi phân tích tập dữ liệu mà kỳ vọng nó tuân theo luật Benford. Đối với 
các phép phân tích dựa trên luật Benford chúng ta sẽ tiến hành phân chia hay phân vùng các số có chữ số bắt đầu giống nhau để kiểm tra, do đó ta có khái niệm như sau (tập $X)$.

Vùng i là tập hợp tất cả các trị số có chũ số bắt đầu là i trên tập dũ liệu kế toán được đem đi kiểm tra

Kí hiệu: $S_{i}=\left\{x_{k}\right.$ thuộc tập $\left.X \mid \operatorname{left}\left(x_{k}\right)=i\right\}$

\section{Các nghiên cứu trước}

Các kết quả nghiên cứu liên quan trước đây của các nhà khoa học trên thế giới đầu tiên phải kể đến là tiến sĩ Mark Nigrini, tiếp đến là Linda Mittermaier, Durtschi, C., and Hillison, W., and Pacini, Lanza, R.,... Trích lược nội dung nghiên cứu của các tác giả được thể hiện trong bảng 2 dưới.

Uu điểm của các nghiên cưu: Các kết quả nghiên cứu chủ yếu là khám phá và minh chứng luật Benford, đồng thời định hướng ứng dụng của luật Benford trong việc kiểm tra sự gian lận của số liệu kinh tế nói chung và dữ liệu kế toán nói riêng.

Khuyết điểm: Chưa mô hình hoá hoặc xây dựng mô hình ước lượng sai sót và rủi ro sai sót trọng yếu của các khoản mục kế toán, chưa hệ thống hóa được các phương pháp kiểm định, đánh giá sự phù hợp và hợp lý của các chỉ tiêu trên các báo cáo tài chính. Đặc biệt là mô hình đánh giá tính trung thực của các báo cáo tài chính phù hợp với các công ty đang hoạt động tại Việt Nam.

Điểm mới: Trong nghiên cứu này tác giả sẽ vận dụng kết quả của luật Benford kết hợp với lý thuyết xác suất thống kê mà cốt lõi là các phép ước lượng, kiểm định giả thiết thống kê và thống kê Bayes để xây dựng các phương pháp phát hiện các vùng có sai sót trọng yếu (hoặc tiềm ẩn sự gian lận) trong số liệu kế toán và ước lượng mức sai sót (cả số tương đối và tuyệt đối). Từ đó, chỉ ra các tham số đặc trưng nhằm hướng dẫn kiểm toán viên trong việc kiểm tra chi tiết dữ liệu.

Bảng 2: Một số nghiên cứu có liên quan đến luật Benford và khe hỏng nghiên cứu

\begin{tabular}{|c|c|c|c|c|}
\hline Tác giả & Năm & Tiêu đề & Nội dung nghiên cứu & Khe hỏng nghiên cứu \\
\hline $\begin{array}{l}\text { Nigrini, M. } \\
\text { J. }\end{array}$ & 1996 & $\begin{array}{l}\text { A taxpayer compliance } \\
\text { application of Benford's Law. } \\
\text { Journal of the American } \\
\text { Taxation Association, 18(1), } \\
\text { 72-91 }\end{array}$ & $\begin{array}{l}\text { Úng dụng luật Benford } \\
\text { trong Kiểm tra dữ liệu } \\
\text { thuế thu nhập của } \\
\text { người dân Mỹ }\end{array}$ & $\begin{array}{l}\text { Chưa xây dựng mô hình ước } \\
\text { lượng sai sót và rủi ro sai sót } \\
\text { trơng yếu của các khoản mục } \\
\text { kế toán để đánh giá tính trung } \\
\text { thực và hợp lý trên báo cáo tài } \\
\text { chính }\end{array}$ \\
\hline Allaart, P. & 1997 & $\begin{array}{l}\text { An invariant-sum } \\
\text { characterizarion of Benford's } \\
\text { Law. Journal of } \\
\text { AppliedProbability, 34, 288- } \\
291 \text {. }\end{array}$ & $\begin{array}{l}\text { Đặc điểm bất biến của } \\
\text { luật Benford }\end{array}$ & $\begin{array}{l}\text { Chưa xây dựng mô hình ước } \\
\text { lượng sai sót và rủi ro sai sót } \\
\text { trơng yếu của các khoản mục } \\
\text { kế toán để đánh giá tính trung } \\
\text { thực và hợp lý trên báo cáo tài } \\
\text { chính }\end{array}$ \\
\hline $\begin{array}{l}\text { Durtschi, C., } \\
\text { Hillison, W., } \\
\text { \& Pacini, C }\end{array}$ & 2004 & $\begin{array}{l}\text { The effective use of Benford's } \\
\text { Law to assist indetecting fraud } \\
\text { in accounting data. Journal of } \\
\text { Forensic Accounting, 5(1), } \\
\text { 17-34. }\end{array}$ & $\begin{array}{l}\text { Úng dụng luật Benford } \\
\text { để phát hiện gian lận } \\
\text { trong dữ liệu kể toán }\end{array}$ & $\begin{array}{l}\text { Chưa xây dựng mô hình ước } \\
\text { lượng sai sót và rủi ro sai sót } \\
\text { trơng yếu của các khoản mục } \\
\text { kế toán đề đánh giá tính trung } \\
\text { thực và hợp lý trên báo cáo tài } \\
\text { chính }\end{array}$ \\
\hline $\begin{array}{l}\text { Cleary, R., } \\
\text { \& } \\
\text { Thibodeau, } \\
\text { J. }\end{array}$ & 2005 & $\begin{array}{l}\text { Applying digital analysis using } \\
\text { Benford's Law to detect fraud: } \\
\text { The dangers of type I errors. } \\
\text { Auditing: Journal of Practice } \\
\text { and Theory, 24(1), 77-81. }\end{array}$ & $\begin{array}{l}\text { Úng dụng luật Benford } \\
\text { để phát hiện gian lận } \\
\text { trong dữ liệu kế toán: } \\
\text { Sai lầm loại } 1 \text { của kiểm } \\
\text { toán }\end{array}$ & $\begin{array}{l}\text { Chưa xây dựng mô hình ước } \\
\text { lượng sai sót và rủi ro sai sót } \\
\text { trơng yếu của các khoản mục } \\
\text { kế toán để đánh giá tính trung } \\
\text { thực và hợp lý trên báo cáo tài } \\
\text { chính }\end{array}$ \\
\hline $\begin{array}{l}\text { Miller, S., \& } \\
\text { Nigrini, M. }\end{array}$ & 2008 & $\begin{array}{l}\text { Order statistics and Benford's } \\
\text { Law. International Journal of } \\
\text { Mathematics and } \\
\text { Mathematical Sciences, doi: } \\
10.1155 / 2008 / 382948\end{array}$ & $\begin{array}{l}\text { Giải thích luật Benford } \\
\text { và các quan hệ lý } \\
\text { thuyết thống kê }\end{array}$ & $\begin{array}{l}\text { Chưa xây dựng mô hình ước } \\
\text { lượng sai sót và rủi ro sai sót } \\
\text { trơng yếu của các khoản mục } \\
\text { kế toán để đánh giá tính trung }\end{array}$ \\
\hline
\end{tabular}




\begin{tabular}{|c|c|c|c|c|}
\hline Tác giả & Năm & Tiêu đề & Nội dung nghiên cứu & Khe hỏng nghiên cứu \\
\hline & & & & $\begin{array}{l}\text { thực và hợp lý trên báo cáo tài } \\
\text { chính }\end{array}$ \\
\hline $\begin{array}{l}\text { Nigrini, M., } \\
\text { \& Miller, S. }\end{array}$ & 2009 & $\begin{array}{l}\text { Data diagnostics using second- } \\
\text { order tests of Benford's Law. } \\
\text { Auditing: Journal of Practice } \\
\text { and Theory, 28(2), 305-324. }\end{array}$ & $\begin{array}{l}\text { Kiểm tra dữ liệu sử } \\
\text { dụng các phép kiểm } \\
\text { định chữ số thứ } 2 \text { của } \\
\text { Luật Benford }\end{array}$ & $\begin{array}{l}\text { Chưa xây dựng mô hình ước } \\
\text { lượng sai sót và rủi ro sai sót } \\
\text { trợng yếu của các khoản mục } \\
\text { kế toán để đánh giá tính trung } \\
\text { thực và hợp lý trên báo cáo tài } \\
\text { chính }\end{array}$ \\
\hline $\begin{array}{l}\text { Nigrini, } \mathrm{M} . \\
\mathrm{J} .\end{array}$ & 2011 & $\begin{array}{l}\text { Forensic analytics: Methods } \\
\text { and techniques for forensic } \\
\text { accounting investigations. } \\
\text { Hoboken, NJ: Wiley. }\end{array}$ & $\begin{array}{l}\text { Phương pháp và kỹ } \\
\text { thuật điều tra tội phạm } \\
\text { kế toán }\end{array}$ & $\begin{array}{l}\text { Chưa xây dựng mô hình ước } \\
\text { lượng sai sót và rủi ro sai sót } \\
\text { trọng yếu của các khoản mục } \\
\text { kế toán để đánh giá tính trung } \\
\text { thực và hợp lý trên báo cáo tài } \\
\text { chính }\end{array}$ \\
\hline
\end{tabular}

Nguồn: tác giả tổng hợp

\section{PHƯƠNG PHÁP NGHIÊN CÚU}

Phương pháp nghiên cứu định tính kết hợp với nghiên cứu định lượng dựa trên cơ sở luật Benford và lý thuyết xác suất thống kê mà cốt lõi là xác suất đầy đủ, công thức xác suất Bayes, phương pháp ước lượng, phương pháp kiểm định.

\subsection{Nghiên cứu định tính}

Nghiên cứu đã thực hiện thảo luận ý kiến dựa trên cơ sở các chuẩn mực kiểm toán của Việt nam, lý thuyết xác suất thống kê và tham khảo ý kiến của các chuyên gia về kế toán, kiểm toán và một số đồng nghiệp là giảng viên khoa Kế toán Kiểm toán, khoa Khoa học Cơ bản của trường Đại học Công nghiệp Tp.HCM (phụ lục 1). Mục tiêu của phương pháp này là nhận diện được tầm quan trọng của các thủ tục (phương pháp kiểm toán) kiểm toán bằng máy tính. Đồng thời thiết lập hay xây dựng hệ thống các công thức tính toán và ước lượng các tham số đặc trưng cần thiết cho đánh giá sai sót trên từng khoản mục kế toán. Trong quá trình nghiên cứu lý thuyết hay nghiên cứu định tính, tác giả đã tiến hành xây dựng và thiết lập các công thức tính toán các chỉ số cũng như các phép kiểm tra (kiểm định) các kết quả từ số liệu kế toán.

\subsection{Nghiên cứu định lượng}

Vận dụng các phương pháp thống kê như phương pháp thu thập số liệu công ty (Nhật ký chung), tổng hợp, xử lý và phân tích dữ liệu bằng phần mềm MS Excel 2010 (sau khi đã cài đặt các công thức - phần mềm phân tích dữ liệu Excel).

Tác giả đã nghiên cứu thực nghiệm trên tập số liệu nhật ký chung của hơn 29 công ty được cung cấp bởi các công ty kiểm toán và cơ quan Thuế của Việt nam như: Cục Thuế TP.HCM, CNMNCông ty TNHH Kiểm toán và Định giá Thăng Long (T.D.K) - Chi nhánh Sài Gòn và chi nhánh Đồng Nai, Công ty Dịch vụ Kế toán và Phát triển đào tạo NETVIET.

Về phương pháp phân tích định lượng, tác giả đã mô hình hoá các công thức tính toán (các công thức đã được trình bày trong mục 4.2) và ước lượng trên phần mềm MS Excel 2010. Phương pháp nghiên cứu định lượng thể hiện cụ thể qua các bước như sau:

Bước 1: Thu thập dũ liệu nghiên cúu

Dũ liệu nghiên cúu là Nhật ký chung hoặc nhật ký dữ liệu của doanh nghiệp.

Tập dĩu liệu kiểm tra là dữ liệu theo khoản mục hay chỉ tiêu kế toán, ví dụ: doanh thu, chi phí bán hàng, thuế,... là các tập số liệu thống kê của các doanh nghiệp đã được ghi nhận trong quá khứ về các nghiệp vụ phát sinh của kế toán, tài chính, thuế,...Các tập số liệu này là cơ sở để các đơn vị lập báo cáo nói chung và báo cáo tài chính nói riêng. Chính vì vậy, để đánh giá sự trung thực của các báo cáo, chúng ta sẽ tiến hành đánh giá theo từng chỉ tiêu (khoản mục) trên báo cáo dựa trên cơ sở số liệu phát sinh được ghi nhận của công ty (Nhật ký chung hay Nhật ký dữ liệu phát sinh). 
Bước 2: Phân tích định lương

Trong bước này, tác giả tiến hành 2 phép phân tích: phân tích tiên nghiệm (phân tích thuận) và phân tích hậu nghiệm (phân tích ngược) như sau:

Phân tích tiên nghiệm: sau khi đã xác định được tập số liệu nghiên cứu, ta tiến hành vận dụng các phương pháp xác suất thông kê để tính toán và ước lượng các tham số cơ bản hay tham số đặc trưng như: tỷ lệ của các chũ số đầu theo Benford và thưc tế, khoảng tin cây của các tỷ lệ, tỷ lệ sai sót của tùng phân vùng và cho khoản muc.Sau đó tiến hành kiểm định các giả thiết thống kê dựa trên cơ sở định luật Benford nhằm khẳng định các sai sót là có ý nghĩa thống kê, tức là bác bỏ hay chấp nhận giả thiết thống kê. Giả thiết thống kê là một loại thông tin có liên quan đến tập dữ liệu nghiên cứu mà kiểm toán viên cần phải kiểm tra tính xác thực của nó thông qua số liệu thống kê.

Kiểm tra hậu nghiệm: khi đã xác định được các mức sai sót trên từng khoản mục kế toán thì việc tiếp theo của kiểm tra hậu nghiệm là tính toán, ước lượng khả năng sai sót đó rơi vào vùng nào với xác suất bao nhiêu. Giá trị xác suất hậu nghiệm rất có ý nghĩa đối với kiểm toán viên vì nó gợi ý cho kiểm toán viên biết là nên ưu tiên kiểm tra tại vùng nào để có thể tìm ra chứng cứ cho sự sai sót.

Bước 3: Đánh giá sai sót \& Kết luận

Đánh giá có sự sai sót trong dữ liệu kế toán hay không, kiểm toán viên cần phải xác định mức trọng yếu tổng thể và mức trọng yếu thực hiện. Cuối cùng, kiểm toán viên cần hết sức thận trọng trong việc xem xét kết quả, kết hợp với các phương pháp kiểm tra để đưa ra nhận xét và kết luận hợp lý về các nội dung và báo cáo tài chính của doanh nghiệp.

\subsection{Quy trình phân tích và ra quyết định kiểm toán}

Quy trình thực hiện thể hiện qua ba giai đoạn cơ bản như Hình 3

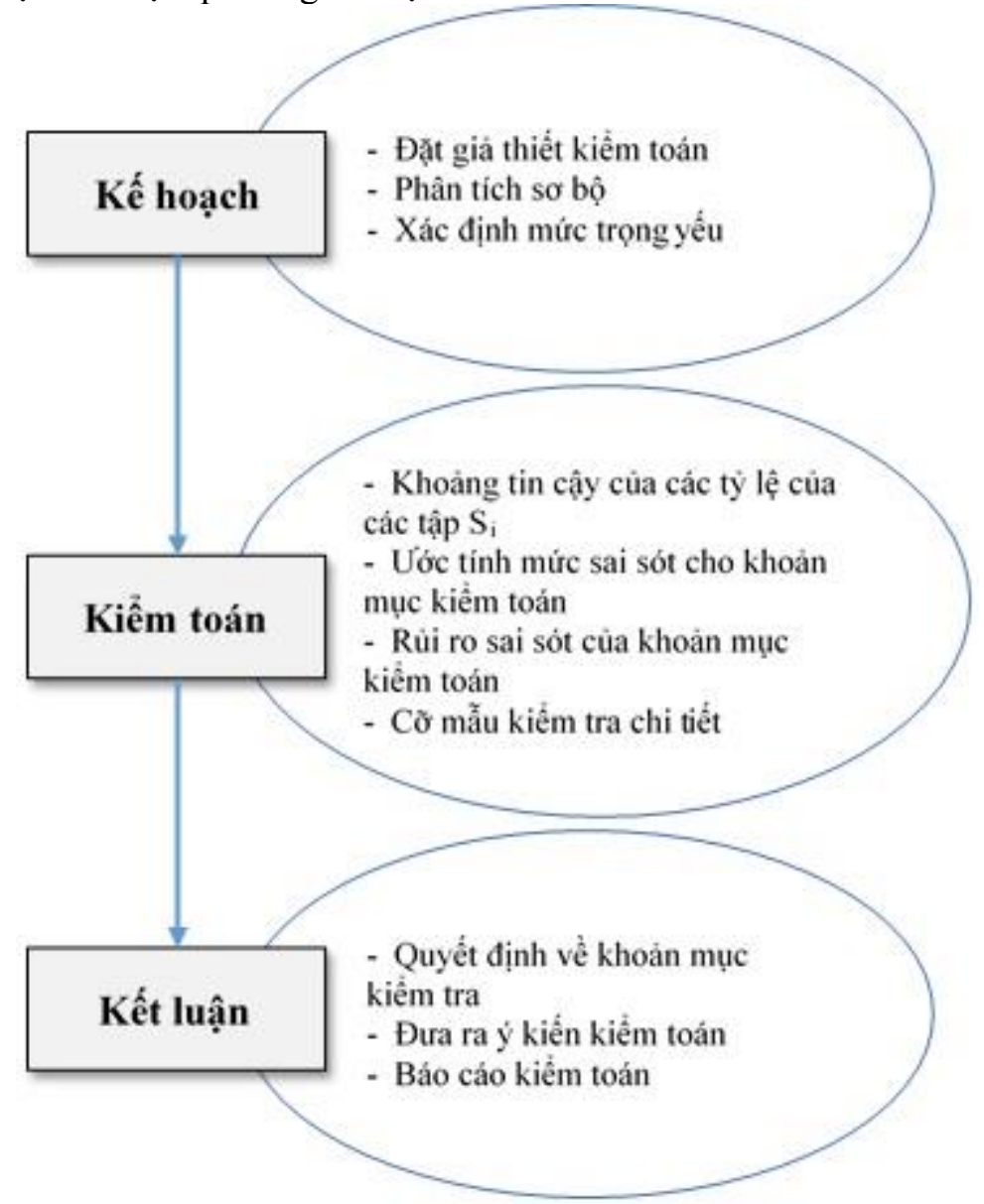

Hình 3: Quy trình phân tích và ra quyết định kiểm toán 
Giai đoạn kế hoạch: Kiểm toán viên (KTV) thu thập dữ liệu (nhật ký chung) của công ty khách hàng được kiểm toán, thực hiện bước phân tích sơ bộ bằng phương pháp đồ thị/biểu đồ như biểu đồ Benford, scatle, radar,... để nhận diện chung về dữ liệu của các khoản mục dự kiến sẽ kiểm tra, làm cơ sở cho việc xác lập mức trọng yếu tổng thể và mức trọng yếu thực hiện. Đồng thời, KTV cũng viết các giả thiết kiểm toán trong giai đoạn này.

Giai đoạn kiểm toán: KTV thực hiện tính toán, xác định khoảng tin cậy cho các tỷ lệ của các tập $\mathrm{S}_{\mathrm{i}}$ của khoản mục kiểm tra. Ước tính mức sai sót và rủi ro có sai sót trọng yếu cho khoản mục. Kết quả kiểm tra mà KTV không chấp nhận (bác bỏ) giả thiết kiểm toán thì KTV phải thực hiện kiểm toán chi thiết (điều tra chi tiết), khi đó KTV cần xác định cỡ mẫu kiểm tra để kết quả kiểm tra đảm bảo độ tin cậy cho trước.

Giai đoạn kết luận: Cuối cùng, KTV cần tổng hợp các kết quả kiểm tra của các khoản mục (hay chỉ tiêu) để đưa ra kết luận, ý kiến kiểm toán và viết báo cáo kiểm toán.

\subsubsection{Khoảng tin cậy cho tỷ lệ các tập $\mathrm{S}_{\mathrm{i}}$ và mức sai sót của khoản mục kiểm toán}

\subsubsection{Khoảng tin cậy cho tỷ lệ của các tập $S_{i}$}

Ước tính tỷ lệ của tập số liệu $S_{i}$ thuộc khoản muc kiểm toán

Xác suất Benford chính là tỷ lệ kỳ vọng của các chữ số đầu. Kiểm toán viên có thể sử dụng tỷ lệ Benford làm cơ sở để ước tính các sai sót của dữ liệu đối với khoản mục kiểm tra trong quá trình thực hiện phân tich cơ bản. Khi nghiên cứu trên các tập số liệu mà kỳ vọng tuân theo luật Benford thì kết quả tính toán tỷ lệ các chữ số đầu xuất hiện có thể không chính xác bằng giá trị xác suất được tính toán từ công thức (1), vì các con số trong cuộc sống là các số thay đổi ngẫu nhiên. Chính vì vậy, chúng ta cần phải ước tính (hoặc ước lượng). Trong phép ước lượng chúng ta sẽ thực hiện cả hai loại, đó là ước lượng điểm và ước lượng khoảng (hay còn gọi khoảng tin cậy) cho các tỷ lệ thực đó dựa trên luật Benford. Kiểm toán viên ước tính tỷ lệ kỳ vọng (ước lượng điểm) dựa theo luật Benford với công thức (1) trên. Sử dụng công thức này thì tỷ lệ các số bắt đầu với chữ số 1 thì khoảng $30,1 \%$ trong khi tỷ lệ các số bắt đầu với chữ số 9 thì chỉ 4.6\% (bảng 1). Việc kiểm toán viên chỉ dựa trên những giá trị ước lượng điểm khó có thể đưa ra những nhận xét chuẩn xác về thông tin kiểm tra, vì dữ liệu thực tế nói chung sẽ có sự sai lệch nhất định so với các trị số Benford. Các tỷ lệ quan sát thực tế sẽ phân tán tập trung quanh tỷ lệ kỳ vọng của nó và độ lệch tiêu chuẩn của các tỷ lệ kỳ vọng được xác định theo công thức sau [4]

$$
s_{i}=\sqrt{\frac{p_{e i} \times\left(1-p_{e i}\right)}{n}}
$$

Với,

$$
\begin{aligned}
& +p_{e i} \text { là tỷ lệ kỳ vọng của } \mathrm{S}_{\mathrm{i}} \text { (theo luật Benford) } \\
& +n \text { là kích thước mẫu (số quan sát) } \\
& +s_{i} \text { là độ lệch chuẩn }
\end{aligned}
$$

Như vậy, các tỷ lệ quan sát thực tế của $\mathrm{S}_{\mathrm{i}}$ sẽ dao động trong khoảng là

$$
p_{e i}-s_{i} \leq p_{i} \leq p_{e i}+s_{i}
$$

Theo quan điểm của các nhà thống kê học thì việc KTV đưa ra quyết định là "bác bỏ" giả thiết kiểm toán thì có thể KTV sẽ mắc phải sai lầm loại 1 [8]. Nghĩa là, KTV bác bỏ giả thiết kiểm toán trong khi giả thiết đó thực tế là đúng(chấp nhận). Vấn đề cần quan tâm lúc này của KTV là chọn "độ chính xác bao nhiêu" để có thể giảm thiểu được rủi ro kiểm toán, vấn đề này chúng ta sẽ thảo luận thêm trong mục tiếp theo dưới (mục 3.3.1.2).

Khoảng tin cậy cho tỷ lệ của các tập $S_{i}$

Câu hỏi đặt ra đối với các Kiểm toán viên là các tỷ lệ của các tập $S_{\mathrm{i}}$ bao nhiêu là hợp lý và có thể chấp nhận được trong bước phân tích cơ bản. Một công cụ có thể hỗ trợ cho KTV là căn cứ vào khoảng tin cậy của nó để đưa ra phán xét chuẩn xác và có cơ sở hơn đối với một tập dữ liệu kế toán được kiểm tra. Phương pháp xác định khoảng tin cậy cho tỷ lệ tổng thể như sau.

Chúng ta sẽ đi ước lượng khoảng tin cậy cho các tỷ lệ tổng thể $\left(p_{i j}\right)$.

Trong đó, $i(i=1,2, . ., 9)$ để chỉ chữ số đầu tiên của số (trị số) và $j$ là khoản mục hay chỉ tiêu kiểm tra. Để đơn giản cho việc gọi tên sau này, ta đặt " $\mathrm{S}_{i j}=\{$ tập các số có chũ số đầu tiên là $i$ của khoản muc $\mathrm{j}$ trên báo cáo sẽ được kiểm tra\}. Để đơn giản ta gọi là tập $\mathrm{S}_{\mathrm{i}}$ (đối với khoản mục kiểm toán cụ thể) thay cho $\mathrm{S}_{\mathrm{ij}}$. 
Với độ tin cậy $1-\alpha$ cho trước, ta xác định độ chính xác của phép ước lượng $p_{i j}$ hay $p_{i}$ là [6]

$$
\varepsilon_{i}=t_{\alpha} \times \sqrt{\frac{p_{e i} \times\left(1-p_{e i}\right)}{n}}
$$

Trong đó,

$+p_{e i}$ là tỷ lệ kỳ vọng của $\mathrm{S}_{i}$ (theo luật Benford)

$+n(\geq 30)$ là kích thước mẫu (số quan sát)

$+\varepsilon_{i}$ là độ chính xác của phép ước lượng

Khi đó, khoảng tin cậy của các tỷ lệ $p_{i}$ (mục kiểm tra j) là

$$
p_{e i}-\varepsilon_{i}<p_{i}<p_{e i}+\varepsilon_{i}
$$

Sau khi đã xác định được khoảng tin cậy cho các tỷ lệ, kiểm toán viên có thể xem xét và đánh giá như sau. Nếu tỷ lệ các chữ số đầu được tính từ tập số liệu của khoản mục kế toán thuộc khoảng tin cậy thì đưa ra quyết định "chấp nhận", tức chấp nhận các số (giá trị) kế toán bắt đầu với chữ số i $(\mathrm{i}=1,2,3, \ldots, 9)$ hay chấp nhận tập số $\mathrm{S}_{\mathrm{i}}$, ngược lại kiểm toán đưa ra quyết định là "không chấp nhận" hay "bác bỏ" tập số $\mathrm{S}_{\mathrm{i}}$. Trường hợp kiểm toán viên đưa ra quyết định "không chấp nhận" tập số $\mathrm{S}_{\mathrm{i}}$ thì phải tiến hành các cuộc điều tra chi tiết hoặc phân tích sâu dữ liệu để xác định nguyên nhân của sai lệch đó.

\subsubsection{2 Ước tính mức sai sót cho khoản mục kiểm toán}

Uớc tính tỷ lẹ sai lệch vuoơt nguõng của tập $S_{i}$

Như đã trình bày trong phần trước, tỷ lệ Benford là những giá trị kỳ vọng, nó được xác định bởi công thức (1). Các tỷ lệ của tập $S_{\mathrm{i}}$ trong thực tế sẽ có sai lệch so với tỷ lệ kỳ vọng. Do đó, để xác định phần tỷ lệ sai sót thực tế của tập $\mathrm{S}_{\mathrm{i}}$, chúng ta phải điều chỉnh mức sai lệch cho phép, mức sai lệch cho phép đối với mỗi tỷ lệ $\mathrm{p}_{\mathrm{i}}$ của tập $\mathrm{S}_{\mathrm{i}}$ chính là độ sai lệch tiêu chuẩn kỳ vọng của $\mathrm{p}_{\mathrm{i}}$.

Nếu gọi pie là tỷ lệ kỳ vọng của tập $S_{i}$ (tỷ lệ tính theo luật Benford), $\mathrm{s}_{\mathrm{i}}$ là độ lệch tiêu chuẩn của nó (mức sai lệch cho phép) và $\mathrm{p}_{\mathrm{ij}}$ là tỷ lệ thực của nó. Khi đó, tỷ lệ sai lệch vượt ngưỡng của tập $\mathrm{S}_{\mathrm{i}}$ được xác định theo công thức sau [12].

Trong đó,

$$
f_{\text {err }(i)}=\operatorname{Max}\left(\left|p_{i j}-p_{i e}\right|-s_{i}, 0\right)
$$

$+f_{\text {err }(i)}$ là tỷ lệ sai lệch vượt ngưỡng cho phép đối với tập số $\mathrm{S}_{\mathrm{i}}$.

$+\mathrm{s}_{\mathrm{i}}$ là độ lệch tiêu chuẩn và được xác định bởi công thức (2)

và $f_{\operatorname{err}(i)}$ bằng 0 nếu $\left|p_{i}-p_{i e}\right|-s_{i}<0$, ngược lại $f_{\text {err }(i)}$ bằng $\left|p_{i}-p_{i e}\right|-s_{i}$.

Nếu $p_{i j}>p_{i e}+s_{i}$ thì ta gọi là sai lệch dương (hay còn gọi là tỷ lệ ghi khống), đặc biệt trong trường hợp $f_{\operatorname{err}(i)}$ khác 0 một cách đáng kể, điều này cho thấy tập $\mathrm{S}_{\mathrm{i}}$ đang tiềm ẩn rủi ro sai sót hoặc có gian lận. Ngược lại, nếu $p_{i j}<p_{i e}-s_{i}$ thì ta gọi là sai lệch âm (hay còn gọi là tỷ lệ ghi thiếu). Trong thực tế kiểm toán viên muốn tìm ra nghiệp vụ sai sót trong tập $S_{i}$ thì phải căn cứ vào trường hợp lệch dương tức $p_{i j}>$ $p_{i e}+s_{i}$.

Uớc tính múc sai sót cho khoản mục

Ước tính mức sai sót tương đối trên tập $\mathrm{S}_{\mathrm{i}}$ chúng ta thực hiện theo phương pháp sau.

Nếu đặt, $\mathrm{V}_{\mathrm{i}}$ là tổng giá trị của tập $\mathrm{S}_{\mathrm{i}}$ và tổng giá trị của khoản mục đang kiểm tra là $\sum_{i=1}^{9} V_{i}$. Khi đó

Nếu $p_{i j}-p_{i e}-s_{i}>0$ thi

$$
d_{i}=\frac{f_{\operatorname{err}(i)} \times V_{i}}{\sum_{i=1}^{9} V_{i}}
$$

với $d_{i}$ là mức sai sót tương đối của tập $\mathrm{S}_{\mathrm{i}}$ và $f_{\mathrm{err}(i)} \times V_{i}$ là mức sai sót tuyệt đối (kỳ vọng) trong trường hợp này

Ngươc lại, $p_{i j}-p_{i e}+s_{i}<0$ 


$$
d_{i}=\frac{f_{\operatorname{err}(i)} \times\left(1+f_{\operatorname{err}(i)}\right) \times V_{i}}{\sum_{i=1}^{9} V_{i}}
$$

với $f_{\text {err }(i)} \times\left(1+f_{\text {err }(i)}\right) \times V_{i}$ là mức sai sót tuyệt đối (kỳ vọng) trong trường hợp này

Vấn đề tiếp theo mà kiểm toán viên cần xem xét là mức sai sót của khoản mục kiểm toán và mức trọng yếu của nó. Như vậy, kiểm toán viên phải ước tính được mức sai sót tương đối cho khoản mục kiểm toán. Phương pháp ước tính mức sai sót tương đối cho khoản mục được thực hiện theo công thức sau

$$
f_{j}=\sum_{i=1}^{9} d_{i}
$$

Trong đó,

$+\mathrm{f}_{\mathrm{j}}$ là mức sai sót tương đối của khoản mục $\mathrm{j}$

$+\mathrm{d}_{\mathrm{i}}$ là mức sai sót tương đối của tập $\mathrm{S}_{\mathrm{i}}$

\subsubsection{Rủi ro sai sót của khoản mục kiểm toán và cở mẫu kiểm tra chi tiết}

\subsubsection{Rủi ro sai sót của khoản mục kiểm toán}

Các phương pháp tính đều dựa trên nền tảng của lý thuyết xác suất thống kê. Tuy nhiên về quan điểm của các nhà Thống kê thì thường quan tâm đến tần số và tần suất. Trong khi đó, quan điểm các KTV thì quan tâm đến giá trị của các sai lệch hơn. Trong nhiều trường hợp tỷ số nhỏ (có thể nhỏ hơn mức trọng yếu) nhưng mức sai sót tương đối của nó lớn thì KTV vẫn phải thận trọng và thường thực hiện các kiểm tra chi tiết để tìm hiểu nguyên nhân. Hơn nữa, đôi lúc mức sai sót của mục kiểm tra nhỏ hơn mức trọng yếu của nó nhưng khả năng (hay xác suất) xảy ra sai sót trên khoản mục đó chưa chắc đã nhỏ. Như vậy, việc kết hợp các các thông tin về xác suất hay khả năng tiềm ẩn sai sót trên khoản mục cũng rất hữu ích cho KTV trong quyết định kiểm toán. Nội dung tiếp theo, chúng ta sẽ thảo luận thêm phương pháp ước tính xác sai sót tiềm ần [12].

Nếu gọi $A_{i}$ là biến cố "một số có chũ số đầu là i được lấy ra tù tập số liệu của khoản muc để kiểm tra" và A là biến cố "số lấy ra tù tập số liệu là sai lệch so với giá trị kiểm toán (trị thưc)". Khi đó, tập các biến cố $A_{i}$ là một hệ biến cố đầy đủ và xung khắc từng đôi.

Phương pháp tính xác suất sai sót của khoản mục được dựa trên cơ sở của công thức xác suất đầy đủ và có thể xem $\mathrm{P}\left(\mathrm{A}_{\mathrm{i}}\right)$ là tỷ lệ của tập số $\mathrm{S}_{\mathrm{i}}$ và $\mathrm{P}\left(\mathrm{A} \mid \mathrm{A}_{\mathrm{i}}\right)$ là tỷ lệ sai sót trên tập $\mathrm{S}_{\mathrm{i}}$ và

$+\mathrm{P}(\mathrm{A})$ là xác suất sai sót cho khoản mục kiểm toán

$+p_{i j}$ tỷ lệ (tỷ trọng) của tập $\mathrm{S}_{\mathrm{i}}$ trong khoản mục kiểm toán $\mathrm{j}$ nào đó

$+f_{\operatorname{err}(i)}$ là tỷ lệ sai lệch của tập số $\mathrm{S}_{\mathrm{i}}$.

Khi đó,

$$
\begin{gathered}
P(A)=\sum_{i=1}^{9} P\left(A_{i}\right) \cdot P\left(A \mid A_{i}\right)=\sum_{i=1}^{9} p_{i j} \times f_{\operatorname{err}(i)} \\
\sum_{i=1}^{9} p_{i j}=1
\end{gathered}
$$

Hơn nữa, ta có

với $p_{i j}$ hay đơn giãn là $p_{\mathrm{i}}$ (nếu mặc định khoản mục đang kiểm toán) là tỷ lệ của tập $S_{i}$.

Ngoà ra, KTV còn quan tâm "sai sót" đó có thể xảy ra ở những phân vùng nào với xác suất tương ứng bao nhiêu. Từ đó sẽ định hướng cho việc kiểm tra, kiểm toán nhanh, không mất nhiều thời gian. Áp dụng công thức Bayes để tính xác suất sai sót ở các tập $\mathrm{S}_{\mathrm{i}}$ (xác suất hậu nghiệm). Xác suất sai sót xảy ra trên tập $\mathrm{S}_{\mathrm{i}}$ khi đã biết thông tin về biến cố $\mathrm{A}$, được xác định như sau

$$
P\left(A_{i} \mid A\right)=\frac{P\left(A_{i}\right) \cdot P\left(A \mid A_{i}\right)}{P(A)}=\frac{p_{i} \times f_{\mathrm{err}(\mathrm{i})}}{\sum_{i=1}^{9} p_{i} \times f_{\mathrm{err}(\mathrm{i})}}
$$

\subsubsection{Cơ mẫu kiểm tra chi tiết}


Công thức xác định cỡ mẫu cho kiểm tra chi tiết được tính theo công thức sau [12]

Trong đó,

$$
n_{e i}=t_{\alpha}^{2} \times \frac{p_{e i} \times\left(1-p_{e i}\right)}{\varepsilon^{2}}
$$

$+n_{e i}$ là cơ mẫu

$+t_{\alpha}$ là giá trị tới hạn

$+p_{e i}$ là tỷ lệ kỳ vọng của tập $\mathrm{S}_{\mathrm{i}}$ hay tỷ lệ Benford

$+\varepsilon$ là độ chính xác của phép kiểm tra

Trong một số trường hợp, giá trị của $n_{e i}$ lớn hơn $\mathrm{n}_{\mathrm{i}}$ (số quan sát của tập $\mathrm{S}_{\mathrm{i}}$ ) thì kiểm toán viên nên thực hiện kiểm tra tất cả các chứng từ (hay nghiệp vụ) thuộc tập $S_{\mathrm{i}}$. Ngược lại, thì kiểm toán viên lấy mẫu ngẫu nhiên từ tập $S_{\mathrm{i}}$ và cỡ mẫu bằng $n_{e i}$ tính theo công thức trên để kiểm tra sẽ đảm bảo tính chính xác và độ tin cậy thống kê.

\section{KÊT QUẢ NGHIÊN CÚU}

\subsection{Tổng hợp các kết quả nghiên cứu thực nghiệm đối với dữ liệu kế toán của các doanh nghiệp tại Việt nam}

Tác giả cố gắng thực hiện bước nghiên cứu thực nghiệm này nhằm một lần nữa khẳng định tính ứng dụng hiệu quả của luật Benford đối với các tập dữ liệu kế toán của các công ty tại Việt nam. Từ đó, định hướng cho các nhà khoa học Việt nam tiếp tục nghiên cứu ứng dụng luật Benford kết hợp với các công cụ (lý thuyết) khác nhằm có thể phát triển thêm các thủ tục (hay phương pháp) kiểm toán, tiến đến có thể xây dựng hệ thống thông tin kiểm toán vận dụng trong kiểm toán báo cáo tài chính. Những gợi ý trong nghiên cứu này của tác giả có ý nghĩa quan trọng đối với sự phát triển ngành dịch vụ kiểm toán và đào tạo kiểm toán tại các trường đại học Việt nam. Kết quả nghiên cứu thực nghiệm được tóm lược như sau.

Bước đầu, nghiên cứu tiến hành mã hóa công thức trên Excel 2010, sau đó tiến hành trích lọc dữ liệu của khoản mục doanh thu của từng công ty và thực hiện tính toán các chỉ số, phân tích các nội dung cơ bản như sau:

+ Tính các tỷ lệ pie (tỷ lệ Benford) với i $=1,2, . ., 9$

+ Tính các tỷ lệ $\mathrm{p}_{\mathrm{i}}(\mathrm{i}=1,2, . ., 9)$ đối với dữ liệu của khoản mục doanh thu

+ Ước lượng tỷ lệ sai sót vượt ngưỡng (ferr(i)) của tập $S_{\mathrm{i}}$

+ Ước lượng khoảng tin cậy cho các tỷ lệ pi của tập $S_{i}$

+ Ước lượng mức sai sót tương đối (f) của khoản mục doanh thu

+ Ước lượng rủi ro (xác suất) sai sót đối với khoản mục doanh thu

+ Ước lượng mức sai sót tuyệt đối của khoản mục doanh thu

+ Cuối cùng, để khẳng định tập số liệu kế toán có phù hợp với luật Benford hay không. Tác giả đã sử dụng phương pháp kiểm định bằng khoảng tin cậy kết hợp với trị kiểm định thống kê (thống kê $\mathrm{t}$ student).

+ Để kết luận một sai sót có trọng yếu hay không cần phải so sánh với mức trọng yếu thực hiện của khoản mục kiểm tra.

+ Sau khi đã xác định được mức sai sót tương đối cho khoản mục doanh thu, nghiên cứu tiếp tục tiến hành phân tích chi tiết để tính toán khả năng sai sót xảy ra trên từng tập $S_{\mathrm{i}}$ thuộc khoản mục kiểm tra hay còn gọi là xác suất hậu nghiệm. Thông tin này sẽ giúp cho kiểm toán viên nhanh chóng nhận diện được vùng có thể có chứa sai sót với xác suất tương ứng của nó, theo kinh nghiệm của tác giả và một số chuyên gia thì kiểm toán viên nên ưu tiên kiểm tra những vùng có xác suất cao. Tổng hợp kết quả nghiên cứu định lượng được trình bày trong bảng 3 dưới đây. 
162 THỦ TỤC PHÂN TÍCH KIỂM TOÁN ƯỚC TÍNH SAI SÓT VÀ RỦI RO SAI SÓT TRỌNG YẾU CÁC KHOẢN MỤC KẾ TOÁN DỰA TRÊN CƠ SỞ CỦA LUẬT BENFORD

Bảng 3: Tổng hợp kết quả phân tích sai sót đối với khoản mục doanh thu

\begin{tabular}{|c|c|c|c|c|c|c|}
\hline Doanh nghiệp & $\begin{array}{l}\text { Nguồn } \\
\text { dữ liệu }\end{array}$ & $\begin{array}{c}\text { Số dòng } \\
\text { của dữ liệu }\end{array}$ & $\begin{array}{c}\text { Số quan } \\
\text { sát }\end{array}$ & $\begin{array}{l}\text { Rủi ro sai } \\
\text { sót của } \\
\text { khoản mục }\end{array}$ & $\begin{array}{l}\text { Mức sai sót } \\
\text { tương đối của } \\
\text { khoản mục }\end{array}$ & $\begin{array}{l}\text { Vùng rủi ro có } \\
\text { sai sót trọng yếu }\end{array}$ \\
\hline DRAGON LINE & NKC & 34497 & 16554 & 0.00219 & 0.00281 & $\mathrm{~S}_{8}$ \\
\hline DHL & NKC & 15936 & 127 & 0.02726 & 0.02554 & \\
\hline TOWA DENKI & NKC & 5479 & 180 & 0.00497 & 0.00114 & $\mathrm{~S}_{8}$ \\
\hline TCIT & NKC & 9791 & 1031 & 0.01443 & 0.00875 & $\mathrm{~S}_{1}, \mathrm{~S}_{3}$ \\
\hline SECUDE INTER & NKC & 5394 & 48 & 0.01465 & 0.01072 & $\mathrm{~S}_{4}$ \\
\hline ALCII & NKC & 4520 & 244 & 0.00609 & 0.00563 & $\mathrm{~S}_{6}$ \\
\hline CERAMIC & NKC & 22005 & 1281 & 0.00271 & 0.00299 & \\
\hline GLR Vina & $\mathrm{NKC}$ & 11544 & 372 & 0.00249 & 0.00301 & $\mathrm{~S}_{5}$ \\
\hline HITISA VINA & NKC & 3259 & 77 & 0.01313 & 0.01670 & $\mathrm{~S}_{6}$ \\
\hline JADELUCK & $\mathrm{NKC}$ & 4501 & 313 & 0.00238 & 0.00285 & \\
\hline MAKAVAR & NKC & 4744 & 118 & 0.00037 & 0.00050 & \\
\hline TTKT MITSUBA & NKC & 5541 & 121 & 0.03797 & 0.03749 & $\mathrm{~S}_{1}, \mathrm{~S}_{4}$ \\
\hline NIDERA & NKC & 2103 & 27 & 0.01022 & 0.01213 & \\
\hline COMARCH & NKC & 1406 & 142 & 0.15754 & 0.14118 & $\mathrm{~S}_{4}, \mathrm{~S}_{5}$ \\
\hline WILLICH & NKC & 214 & 0 & & & \\
\hline OTO UY TIN & NKC & 4532 & 1772 & 0.01228 & 0.00798 & $S_{1}$ \\
\hline DGM & NKC & 1462 & 72 & 0.00656 & 0.00779 & $S_{2}$ \\
\hline SAMJUNG & NKC & 3795 & 60 & 0.02173 & 0.00573 & $\mathrm{~S}_{2}$ \\
\hline ADIN SG & NKC & 1099 & 141 & 0.00160 & 0.00023 & \\
\hline LAFARGE & NKC & 39582 & 8934 & 0.02082 & 0.01906 & $S_{1}, S_{6}, S_{9}$ \\
\hline SUOINANG & NKC & 52560 & 14992 & 0.20331 & 0.19012 & $\mathrm{~S}_{2}, \mathrm{~S}_{3}$ \\
\hline TANTAO & NKC & 355 & 0 & & & \\
\hline ISAM VINA & NKC & 78654 & 808 & 0.00538 & 0.00929 & $\mathrm{~S}_{4}$ \\
\hline SEATECO* & NKC & 1527 & 196 & 0.0585 & 0.07214 & $\mathrm{~S}_{3}, \mathrm{~S}_{5}$ \\
\hline QL\&XD ĐB QN- ĐN* & NKC & 2223 & 55 & 0.0774 & 0.08752 & $\mathrm{~S}_{1}, \mathrm{~S}_{5}, \mathrm{~S}_{6}$ \\
\hline CHANTHANH* & NKC & 13075 & 2746 & 0.0856 & 0.08037 & $\mathrm{~S}_{3}, \mathrm{~S}_{4}$ \\
\hline VUOONG THÁI BİNH* & NKC & 10954 & 36 & 0.0712 & 0.10368 & $\mathrm{~S}_{2}, \mathrm{~S}_{9}$ \\
\hline TRONGNHAN* & $\mathrm{NKC}$ & 1126 & 38 & 0.0935 & 0.11578 & $S_{1}, S_{2}, S_{3}$ \\
\hline HUONGSON* & NKC & 6910 & 410 & 0.0736 & 0.09069 & $\mathrm{~S}_{3}, \mathrm{~S}_{5}, \mathrm{~S}_{6}$ \\
\hline
\end{tabular}

Ghi chú: “*”: doanh nghiệp Việt Nam; NKC: nhật ký chung.

Nguồn: kết quả nghiên cúu.

Kết quả nghiên cứu và kiểm tra với 29 nhật ký chung của các doanh nghiệp trên khoản mục doanh thu, cho thấy có 10/29 mẫu dữ liệu doanh thu tuân theo luật Benford số còn lại thì không theo Benford. Qua cuộc nghiên cứu thực nghiệm với kỹ thuật phân tích Benford, một lần nữa cho phép chúng ta khẳng định rằng các tập số liệu kế toán là các tập số Benford hay nói cách khác là tần suất (tỷ lệ) của các tập $\mathrm{S}_{\mathrm{i}}$ thuộc khoản mục kế toán luôn phân bố theo luật Benford. Những tập số liệu kế toán nào không tuân theo luật Benford, Kiểm toán viên có cơ sở để nghi ngờ rằng khoản mục kế toán đó có tiềm ẩn sai sót hay có sự gian lận.

\subsection{Một số kết quả nghiên cứu chi tiết}


Nội dung phần này, tác giả sẽ trình bày các kết quả phân tích chi tiết trên khoản mục doanh thu của ba công ty là Jadeluck, công ty DragonLine và Comarch.

Kết quả thứ nhất, kiểm tra dữ liệu khoản mục doanh thu của công ty Jadeluck. Doanh thu của công ty Jadeluck được thống kê có 313 quan sát (tức có 313 dòng excel hay 313 nghiệp vụ được kế toán ghi nhận). Tiến hành tính toán các tỷ lệ của các tập $S_{\mathrm{i}}$ thuộc tập số liệu doanh thu, chúng ta thu được kết quả như bảng dưới (bảng 4) và đồ thị như hình 4.

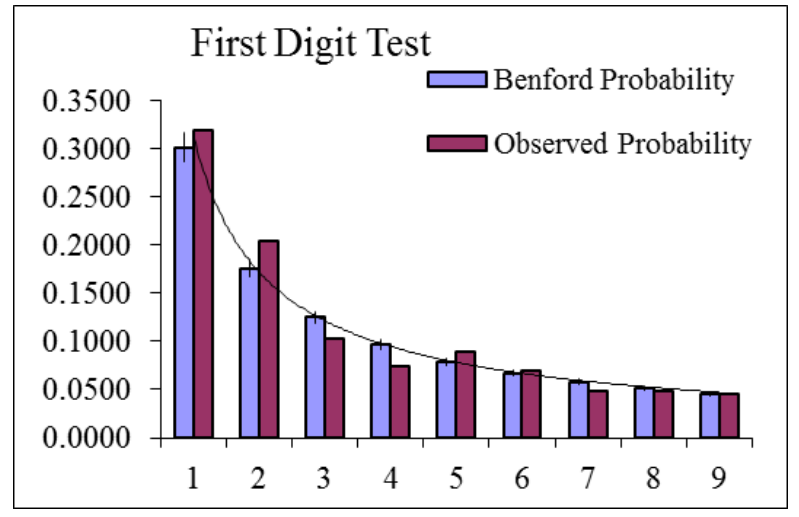

Hình 4: Đồ thị phân phối các chữ số đầu của doanh thu

Bảng 4: Kết quả tính tỷ lệ chữ số đầu với khoản mục doanh thu (công ty Jadeluck)

\begin{tabular}{|c|c|c|c|c|c|}
\hline $\begin{array}{c}\text { Chữ số đầu } \\
\text { tiên }\end{array}$ & $\begin{array}{c}\text { tỷ lệ theo } \\
\text { Benford }\end{array}$ & Cận dưới & Cận trên & Tỷ lệ quan sát & $\begin{array}{c}\text { Quyết định với } \\
\text { độ tin cậy 95\% }\end{array}$ \\
\hline 1 & 0.3010 & 0.2502 & 0.3518 & 0.3195 & Chấp nhận \\
\hline 2 & 0.1761 & 0.1339 & 0.2183 & 0.2045 & Chấp nhận \\
\hline 3 & 0.1249 & 0.0883 & 0.1616 & 0.1022 & Chấp nhận \\
\hline 4 & 0.0969 & 0.0641 & 0.1297 & 0.0735 & Chấp nhận \\
\hline 5 & 0.0792 & 0.0493 & 0.1091 & 0.0895 & Chấp nhận \\
\hline 6 & 0.0669 & 0.0393 & 0.0946 & 0.0703 & Chấp nhận \\
\hline 8 & 0.0580 & 0.0321 & 0.0839 & 0.0479 & Chấp nhận \\
\hline 9 & 0.0512 & 0.0267 & 0.0756 & 0.0479 & Chấp nhận \\
\hline & 0.0458 & 0.0226 & 0.0689 & 0.0447 & Chấp nhận \\
\hline
\end{tabular}

Nguồn: Tác giả tính toán

Quan sát đồ thị hình 4 cho thấy phân bố (tỷ lệ) các số trong tập số doanh thu của công ty Jadeluck khá sát với phân phối theo luật Benford. Đặc biệt, kết quả phân tích được trình bày trong bảng 4 cho thấy các tỷ lệ quan sát đều thuộc phạm vi cho phép (khoảng tin cậy 95\%). Theo quan điểm của Thống kê có thể khẳng định số liệu của của doanh thu công ty Jadeluck là phù hợp, tức có cơ sở để chấp nhận số liệu doanh thu. Điều này cũng khẳng định tập số doanh thu của Jadeluck là tuân theo luật Benford. Tuy nhiên, kiểm toán viên có chấp nhận khoản mục doanh thu của Jadeluck hay không, còn phải xem xét đến mức sai sót tương đối của khoản mục doanh thu có vượt qua ngưỡng trọng yếu hay không. Nếu mức sai sót tương đối 
nhỏ hơn mức trọng yếu thì kiểm toán viên có thể đưa ra quyết định chấp nhận doanh thu của Jadeluck, ngược lại kiểm toán viên sẽ phải khoanh vùng riêng để thực hiện kiểm tra chi tiết. Công việc này chúng ta sẽ thảo luận tiếp trong phần sau đây.

Thực hiện phân tích tỷ lệ sai sót trên khoản mục doanh thu của công ty Jadeluck ta được kết quả như bảng sau (bảng 5).

Bảng 5: Kết quả tính tỷ lệ sai sót các tập Si của khoản mục doanh thu công ty Jadeluck

\begin{tabular}{|c|c|c|c|c|c|c|c|}
\hline $\begin{array}{c}\text { Chữ số } \\
\text { đầu tiên }\end{array}$ & $\begin{array}{c}\text { tỷ lệ theo } \\
\text { Benford }\end{array}$ & $\begin{array}{c}\text { Tỷ lệ quan } \\
\text { sát }\end{array}$ & $\mathbf{s}$ i & $\mathbf{f}_{\text {erri) }}$ & $\begin{array}{c}\text { Mức sai } \\
\text { sót tương } \\
\text { đối }\end{array}$ & $\begin{array}{c}\text { Mức sai } \\
\text { sót tuyệt } \\
\text { đối (lệch } \\
\text { dương) }\end{array}$ & $\begin{array}{c}\text { Mức sai } \\
\text { sót tuyệt } \\
\text { đối (lệch } \\
\text { âm) }\end{array}$ \\
\hline 1 & 0.3010 & 0.3195 & 0.0259276 & 0.0000 & 0.00000 & - & - \\
\hline 2 & 0.1761 & 0.2045 & 0.0215296 & 0.0069 & 0.00160 & $56,527,495$ & - \\
\hline 3 & 0.1249 & 0.1022 & 0.0186894 & 0.0040 & 0.00058 & - & $20,628,780$ \\
\hline 4 & 0.0969 & 0.0735 & 0.0167216 & 0.0067 & 0.00060 & - & $21,408,815$ \\
\hline 5 & 0.0792 & 0.0895 & 0.0152625 & 0.0000 & 0.00000 & - & - \\
\hline 6 & 0.0669 & 0.0703 & 0.0141269 & 0.0000 & 0.00000 & - & - \\
\hline 7 & 0.0580 & 0.0479 & 0.0132111 & 0.0000 & 0.00000 & & - \\
\hline 8 & 0.0512 & 0.0479 & 0.0124526 & 0.0000 & 0.00000 & & - \\
\hline 9 & 0.0458 & 0.0447 & 0.0118110 & 0.0000 & 0.00000 & & - \\
\hline TỔNG & $\mathbf{1 . 0 0}$ & $\mathbf{1 . 0 0}$ & $\mathbf{X}$ & $\mathbf{0 . 0 1 7 6}$ & $\mathbf{0 . 0 0 2 7 8}$ & $\mathbf{5 6 , 5 2 7 , 4 9 5}$ & $\mathbf{4 2 , 0 3 7 , 5 9 5}$ \\
\hline
\end{tabular}

Nguồn: Tác giả tính toán

Theo công thức trên, chúng ta sẽ ước tính mức sai sót cho khoản mục doanh thu như sau

$$
f_{j}=\sum_{i=1}^{9} d_{i}=0.0016+0.0005816+0.0006019=0.00278(0.278 \%)
$$

Như vậy, mức sai sót tương đối của khoản mục doanh thu công ty Jadeluck khoảng $0.28 \%$.

Trong trường hợp mà mức sai sót lớn (vượt mức trọng yếu) và kiểm toán viên muốn tiến hành kiểm tra chi tiết thì KTV nên thực hiện kiểm tra ở những vùng (tập $\mathrm{S}_{\mathrm{i}}$ ) nào với cở mẫu bao nhiêu để có thể tìm ra những bằng chứng cho sự sai sót đó một cách nhanh chóng - không mất nhiều thời gian và chi phí kiểm toán. Câu trả lời là, KTV nên theo hướng dẫn của bảng xác suất hậu nghiệm.

Kết quả nghiên cứu thứ hai trên tập số liệu khoản mục doanh thu của công ty Dragon line với số quan sát là 560. Kết quả phân tích cho thấy mức sai sót khoản mục doanh thu công ty Dragon nhỏ $(0.28 \%)$. Tuy nhiên, kết hợp với kết quả phân tích của bảng 6 thì cho thấy tập số $\mathrm{S}_{8}$ có mức sai sót vượt ngoài phạm vi cho phép (lớn hơn mức trọng yếu phân bổ của nó). Do đó, nếu kiểm toán viên đưa ra quyết định là "không chấp nhận" thì về nguyên tắc việc kiểm tra chi tiết chỉ cần tiến hành đối với tập $\mathrm{S}_{8}$ là được. Tuy nhiên, kiểm toán viên nên thận trọng và cần phải tham khảo hướng dẫn của bảng phân tích hậu nghiệm (bảng 7). Xác suất hậu nghiệm cho biết khả năng mà kiểm toán viên có thể phát hiện sai sót tại các tập kiểm tra $\mathrm{S}_{\mathrm{i}}$ $(\mathrm{i}=1,2,3, \ldots, 9)$. 
Bảng 6: Kết quả phân tích chi tiết khoản mục doanh thu cty Dragon Line

\begin{tabular}{|c|c|c|c|c|c|c|c|c|c|}
\hline $\begin{array}{c}\text { Chứ } \\
\text { số } \\
\text { đầu }\end{array}$ & $\begin{array}{c}\text { tỷ lệ } \\
\text { theo } \\
\text { Benford } \\
\left(\mathrm{p}_{\mathrm{e}}\right)\end{array}$ & $\begin{array}{c}\text { Cận } \\
\text { dưới }\end{array}$ & $\begin{array}{c}\text { Cận } \\
\text { trền }\end{array}$ & $\begin{array}{c}\text { Tỷ lệ } \\
\text { quan } \\
\text { sát } \\
\left(\mathrm{p}_{\mathrm{i}}\right)\end{array}$ & $\begin{array}{c}\text { tỷ lệ } \\
\text { sai sót } \\
\left(\mathrm{f}_{\text {err(i) }}\right)\end{array}$ & $\begin{array}{c}\text { Mức } \\
\text { sai sót } \\
\text { tướng } \\
\text { đối }\end{array}$ & $\begin{array}{c}\text { Trị } \\
\text { kiểmđịnh } \\
(\mathbf{t}-\mathbf{s t a})\end{array}$ & $\begin{array}{c}\text { Mức } \\
\text { trọng } \\
\text { yếu } \\
\text { phân bổ }\end{array}$ & $\begin{array}{c}\text { Quyết } \\
\text { định }\end{array}$ \\
\hline 1 & 0.3010 & 0.2630 & 0.3390 & 0.3125 & 0.0000 & 0.00000 & 0.55 & 0.00344 & $\begin{array}{c}\text { chấp } \\
\text { nhận }\end{array}$ \\
\hline 2 & 0.1761 & 0.1445 & 0.2076 & 0.1571 & 0.0029 & 0.00044 & 1.12 & 0.00173 & $\begin{array}{c}\text { chấp } \\
\text { nhận }\end{array}$ \\
\hline 3 & 0.1249 & 0.0976 & 0.1523 & 0.1161 & 0.0000 & 0.00000 & 0.57 & 0.00128 & $\begin{array}{c}\text { chấp } \\
\text { nhận }\end{array}$ \\
\hline 4 & 0.0969 & 0.0724 & 0.1214 & 0.1071 & 0.0000 & 0.00000 & 0.75 & 0.00118 & $\begin{array}{c}\text { chấp } \\
\text { nhận }\end{array}$ \\
\hline 5 & 0.0792 & 0.0568 & 0.1015 & 0.0750 & 0.0000 & 0.00000 & 0.29 & 0.00083 & $\begin{array}{c}\text { chấp } \\
\text { nhận }\end{array}$ \\
\hline 6 & 0.0669 & 0.0462 & 0.0876 & 0.0500 & 0.0064 & 0.00029 & 1.52 & 0.00055 & $\begin{array}{c}\text { chấp } \\
\text { nhận }\end{array}$ \\
\hline 7 & 0.0580 & 0.0386 & 0.0774 & 0.0571 & 0.0000 & 0.00000 & 0.00 & 0.00063 & $\begin{array}{c}\text { chấp } \\
\text { nhận }\end{array}$ \\
\hline 8 & 0.0512 & 0.0329 & 0.0694 & 0.0786 & 0.0181 & 0.00208 & 2.85 & 0.00086 & Bác bỏ \\
\hline 9 & 0.0458 & 0.0285 & 0.0631 & 0.0464 & 0.0000 & 0.00000 & -0.03 & 0.00051 & $\begin{array}{c}\text { chấp } \\
\text { nhận }\end{array}$ \\
\hline & & & Tổng & & & $\mathbf{0 . 0 0 2 8 1}$ & & & \\
\hline
\end{tabular}

Bảng 7: Xác suất hậu nghiệm (công ty Dragon line)

\begin{tabular}{|c|c|c|c|c|c|}
\hline Tập $S_{i}$ & $\begin{array}{l}\text { XS hậu } \\
\text { nghiệm }\end{array}$ & Giá trị sai sót & GT ghi khống & GT ghi thiếu & Số sai lệch (n) \\
\hline $\mathrm{S}_{1}$ & 0.000 & - & - & - & - \\
\hline $\mathrm{S}_{2}$ & 0.205 & $40,010,104$ & - & $40,010,104$ & - \\
\hline $\mathrm{S}_{3}$ & 0.000 & - & - & - & - \\
\hline $\mathrm{S}_{4}$ & 0.000 & - & - & - & - \\
\hline $\mathrm{S}_{5}$ & 0.000 & - & - & - & - \\
\hline $\mathrm{S}_{6}$ & 0.146 & $26,815,259$ & - & $26,815,259$ & - \\
\hline $\mathrm{S}_{7}$ & 0.000 & - & - & - & - \\
\hline $\mathrm{S}_{8}$ & 0.650 & $190,369,439$ & $190,369,439$ & - & 1 \\
\hline $\mathrm{S}_{9}$ & 0.000 & - & - & - & - \\
\hline \multicolumn{2}{|c|}{ TỔNG } & $257,194,802$ & $190,369,439$ & $66,825,363$ & \\
\hline
\end{tabular}

Nguồn: Tác giả tính toán

Kết quả nghiên cứu thứ ba trên tập số liệu doanh thu của công Cormarch, ta có mức sai sót tương đối cho khoản mục doanh thu $14,1 \%$. Với kết quả này, mức sai sót tương đối khoản mục doanh thu công ty Comarch vượt xa ngưỡng trọng yếu cho phép. Do đó, kiểm toán viên đưa ra quyết định là "không chấp nhận" đối với khoản mục doanh thu và đề nghị lập kế hoạch kiểm tra hay điều tra chi tiết để tìm hiểu nguyên 
nhân của sự sai sót. Việc kiểm toán viên tiến hành kiểm tra chi tiết sẽ được thực hiện trên tập $\mathrm{S}_{4}$ (căn cứ vào kết quả phân tích hậu nghiệm - bảng 8 và kết hợp với biểu đồ - hình 5).

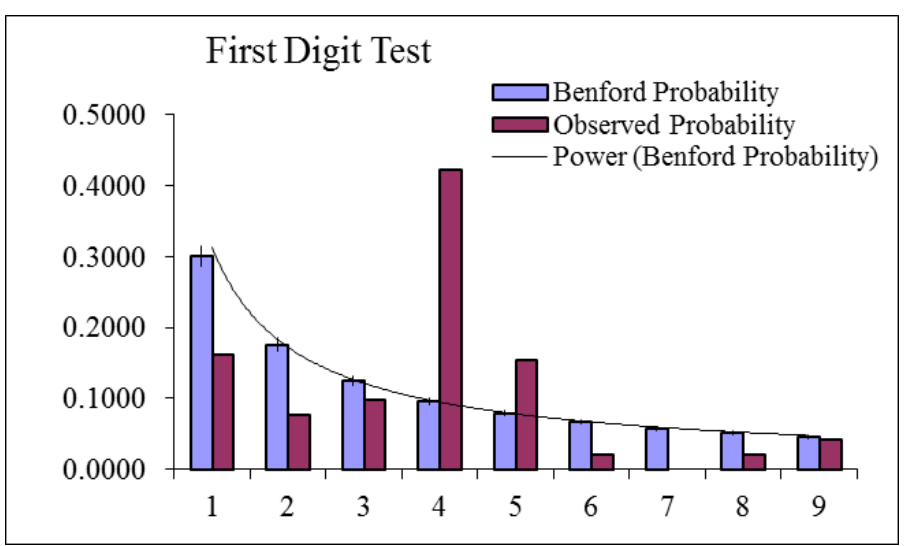

Hình 5: Biểu đồ phân phối của các tập $\mathrm{Si}$ (Comarch)

Bảng 8: Xác suất hậu nghiệm và xác định cỡ mẫu kiểm tra chi tiết (Comarch)

\begin{tabular}{|c|c|c|c|c|}
\hline Digt & XS hậu nghiệm & Giá trị sai sót & $\begin{array}{c}\text { Số quan sát thực tế } \\
\left(\mathbf{n}_{\mathbf{i}}\right)\end{array}$ & $\begin{array}{c}\text { Số kiểm tra chi tiết } \\
\left(\mathbf{n}_{\mathbf{e}}\right)\end{array}$ \\
\hline 1 & 0.103 & $23,553,704$ & 23 & 38 \\
\hline 2 & 0.033 & 750,775 & 11 & 26 \\
\hline 3 & 0.000 & - & 14 & 20 \\
\hline 4 & 0.807 & $84,328,290$ & 60 & 13 \\
\hline 5 & 0.052 & $5,342,128$ & 22 & 12 \\
\hline 6 & 0.003 & $1,687,532$ & 3 & 10 \\
\hline 7 & 0.000 & - & 0 & 8 \\
\hline 8 & 0.002 & 11,253 & 3 & \\
\hline 9 & 0.000 & - & 6 & \\
\hline & TốNG & $\mathbf{1 1 5 , 6 7 3 , 6 8 3}$ & & \\
\hline
\end{tabular}

Nguồn: Tác giả tính toán trên excel 2010

Kiểm toán viên thực hiện kiểm tra chi tiết và để việc kiểm tra đạt được độ chính xác là 0.075 (hay độ tin cậy là $92.5 \%$ ) thì theo công thức cỡ mẫu trên, KTV cần lấy khoảng 16 quan sát thuộc tập $\mathrm{S}_{4}$ để kiểm tra chi tiết.

\subsection{So sánh hai phương pháp kiểm toán}

Để thuận tiện trong việc so sánh các phương pháp kiểm toán, nhóm tác giả thực hiện đặt tên như sau:

Thực trạng phương pháp kiểm toán hiện tại của Việt Nam và một số quốc gia trong khu vực châu Á chưa được hỗ trợ mạnh mẽ bởi phần mềm máy tính (ứng dụng công nghệ thông tin) hay còn gọi là phương pháp kiểm toán thủ công. Phương pháp kiểm toán dựa trên cơ sở Luật Benford kết hợp với lý thuyết xác suất thống kê để xây dựng hệ thống công thức tính toán các tham số đặc trưng. Hệ thống các công thức này được mã hóa và cài đặt trên máy tính hỗ trợ công tác kiểm toán gọi là phần mềm (hay ứng dụng) hỗ trợ cho công tác kiểm toán và đặt tên là TestBenford. 
Bảng 5: So sánh hai phương pháp kiểm toán

\begin{tabular}{|l|l|l|}
\hline \multicolumn{1}{|c|}{$\begin{array}{c}\text { Nội dung } \\
\text { so sánh }\end{array}$} & \multicolumn{1}{c|}{$\begin{array}{c}\text { Phương pháp kiểm toán } \\
\text { thủ công }\end{array}$} & \multicolumn{1}{c|}{ TestBenford } \\
\hline Chi phí đầu tư ban đầu & Thấp & Khá cao \\
\hline Kỹ thuật thực hiện & Thủ công/bằng tay là chủ yếu & Máy tính là chủ yếu \\
\hline Tính khoa học và thời đại & Không & $\begin{array}{l}\text { Khoa học và có tính hiện } \\
\text { đại }\end{array}$ \\
\hline Phạm vi kiểm tra & $\begin{array}{l}\text { Chọn mẫu (kích thước mẫu thường } \\
\text { không đảm bảo - không đủ lớn) }\end{array}$ & $\begin{array}{l}\text { Tống thể (nhật ký chung - } \\
\text { tất cả) }\end{array}$ \\
\hline Thời gian kiểm tra & Mất nhiều thời gian & Ít tốn thời gian \\
\hline Chi phí kiểm tra & Khá lớn & Nhỏ (tiết kiệm đáng kể) \\
\hline $\begin{array}{l}\text { Uớc lượng mức sai sót (số tương } \\
\text { đối và tuyệt đối) cho từng khoản } \\
\text { mục }\end{array}$ & $\begin{array}{l}\text { Khó thực hiện hoặc tính toán phức } \\
\text { tạp }\end{array}$ & $\begin{array}{l}\text { Thực hiện dễ dàng, nhanh } \\
\text { chóng bằng máy tính }\end{array}$ \\
\hline Độ tin cậy kết quả kiểm toán & Thấp & Cao \\
\hline
\end{tabular}

\section{THẢO LUẬN VÀ KẾT LUẬN}

\section{Thảo luận}

Có hai trường hợp liên quan đến việc KTV đưa ra quyết định, đó là:

Trường hợp 1: KTV bác bỏ giả thiết kiểm toán khi dựa vào khoảng tin cậy hay sử dụng phương pháp kiểm định bằng khoảng tin cậy (hoặc phân phối $\mathrm{t}$ - student). Khi đó, KTV có thể sẽ mắc phải sai lầm loại 1 như đã nói ở trên. Lúc này, xác suất sai lầm của KTV mức tối đa cho phép là $\alpha$ (hay còn gọi là mức ý nghĩa).

Trường hợp 2: KTV chấp nhận giả thiết kiểm toán khi sử dụng phương pháp kiểm định bằng khoảng tin cậy (hoặc phân phối $\mathrm{t}$ - student). Khi đó, KTV có thể sẽ mắc phải sai lầm loại 2 . Nghĩa là, KTV chấp nhận giả thiết kiểm toán trong khi giả thiết đó thực tế là sai (bác bỏ).

Nếu $\alpha$ càng bé thì khả năng phạm phải sai lầm loại 1 càng ít, tuy nhiên trong trường hợp này xác xuất sai lầm loại 2 sẽ tăng lên. Chẳng hạn nếu lấy $\alpha=0$ thì sẽ không bác bỏ bất kỳ giả thuyết nào, có nghĩa là không mắc phải sai lầm loại 1 và như vậy xác suất sai lầm loại 2 sẽ đạt cực đại.

Gợi ý, trong trường hợp số liệu kế toán có biểu hiện những bất thường hay KTV nhận thấy có tiềm ẩn gian lận hoặc có sai sót trọng yếu thì KTV có thể mở rộng vùng bác bỏ, nghĩa là KTV sẵn sàng bác bỏ giả thiết kiểm toán. Trường hợp khác KTV nhận thấy số liệu kế toán kiểm tra không có dấu hiệu bất thường hay không có tiềm ẩn rủi ro sai sót thì KTV có thể thu hẹp vùng bác bỏ, nghĩa là KTV sẵn sàng chấp nhận giả thiết kiểm toán.

\section{Kết luận}

Nghiên cứu này xây dựng các phương pháp luận trong kiểm tra và đánh giá các nguồn số liệu kinh tế nói chung và số liệu kế toán nói riêng. Hơn nữa, kết quả nghiên cứu này còn đóng góp và bổ sung vào hệ thống các phương pháp (thủ tục) kiểm toán nhằm giúp kiểm toán viên có cơ sở để đánh giá và kết luận về tính trung thực của số liệu cũng như các báo cáo tài chính.

Nhóm tác giả mong muốn tiếp tục nghiên cứu để đưa ra nhiều phương pháp khác nhau: phân tích mạng Bayesian Networks để đánh giá mức độ trung thức của các báo cáo tài chính, kỹ thuật phân tích data mining để tìm ra những điểm bất thường trong dữ liệu kế toán nhằm có thể phát hiện ra những gian lận... hỗ trợ và giúp kiểm toán viên của Việt Nam có các công cụ đủ mạnh để tiến hành công tác kiểm toán nhanh hơn, hiệu quả hơn nhằm có thể nâng cao năng lực cạnh tranh của các công ty dịch vụ kiểm toán đang hoạt động tại Việt Nam và một số quốc gia trong khu vực. 


\section{TÀI LIỆU THAM KHẢO}

[1] Mark J. Nigrini, Benford's Law, John Wiley \& Sons, Inc, Canada, 2011.

[2] Nigrini, M. J. (1996), A taxpayer compliance application of Benford's Law”, Journal of the American Taxation Association, 18 (1996) 1.

[3] Nigrini, M., Mittermaier, L., The use of Benford's Law as an aid in analytical procedures, Auditing: Journal of Practice and Theory, 16 (1997) 2, 5267.

[4] Durtschi, C., Hillison, W., Pacini, C.(2004), The Effective Use of Benford's Law to Assist in Detecting Fraud in Accounting Data, Journal of Forensic Accounting 1524-5586/Vol. V (2004), 17-34.

[5] Nigrini, M. J. (2011), Forensic analytics - Methods and techniques for forensic accounting investigations, Hoboken, NJ: Wiley.

[6] Hoàng Ngọc Nhậm (2015), Lý thuyết Xác suất và Thống kê toán, Trường Đại học Kinh tế Thành phố Hồ Chí Minh.

[7] Allaart, P. (1997), An invariant-sum characterizarion of Benford's Law, Journal of Applied Probability, 34 (1997), 288-291.

[8] Cleary, R., Thibodeau, J. (2005), Applying digital analysis using Benford's Law to detect fraud: The dangers of type I errors, Auditing: Journal of Practice and Theory, 24 (2005) 1, 77-81.

[9] Miller, S., Nigrini, M. (2008), Order statistics and Benford's Law, International Journal of Mathematics and Mathematical Sciences, doi: 10.1155/2008/382948.

[10] Nigrini, M., Miller, S. (2009), Data diagnostics using second-order tests of Benford's Law, Auditing: Journal of Practice and Theory, 28 (2009) 2, 305-324.

[11] Trần Thị Giang Tân, Vũ Hữu Đức (2014), Kiểm toán, NXB. Kinh tế Thành phố Hồ Chí Minh.

[12] Trần Thứ Ba (2016), Nghiên cưu mô hình phát hiện gian lận số liệu kế toán và uớc lương rủi ro sai sót trọng yếu để đánh giá tính trung thực của các báo cáo tài chính, Báo cáo tổng kết đề tài nghiên cứu khoa học cấp Bộ Công Thương, Việt Nam.

Ngày nhận bài: 24/03/2018

Ngày chấp nhận đăng: 11/10/2018 